\title{
Congratulations to V.L. Vengrinovich
}

DOI: $10.1134 / \mathrm{S} 1061830909080130$

Valerii L'vovich Vengrinovich, the head of the Laboratory of Computational Diagnostics of the Institute of Applied Physics of the National Academy of Sciences of Belarus (Minsk) celebrates his 70th birthday.

A well-known scientist in the field of nondestructive testing, physics of magnetic phenomena, and computational diagnostics, he is the author of more than 300 scientific publications, including two monographs- "Magnetic-Noise Structuroscopy" and "Iterative Methods of Tomography" (in a joint monograph with S.A. Zolotarev). He is the author of more than 40 inventor's certificates and patents. More that 50 articles were published in leading foreign journals. The main field of his studies is the physics of micromagnetic effects, in particular, the Barkhausen effect, the application of this effect in industry, small-angle computer tomography of industrial and biological objects, and special probes for systems for monitoring the state of objects.

Vengrinivich is an elected academician of the International NDT Academy and the Russian Academy of Electrical Engineering Sciences (RAES). He was awarded a Prize of the National Academy of Sciences of Belarus in 2006 and an International Barkhausen Award in 2008 for outstanding scientific results obtained at the boundary of physics, materials science, and electrical engineering.

The editorial board of our journal and the scientific community cordially congratulate V.L. Vengrinovich on his jubilee. 